Список литературы:

1. Скоробогатов А.М. Отчет о раскопках стоянки Черкасская-5 в Павловском районе Воронежской области в 2015 г. // Архив ИА РАН.

2. Скоробогатов А.М., Яниш Е.Ю., Александровский А.Л. Неолитическая стоянка Черкасская-5 на Среднем Дону. Соотношение охоты и рыболовства по фаунистическим и археологическим данным // Стратегии жизнеобеспечения в каменном веке, прямые и косвенные свидетельства рыболовства и собирательства: мат-лы междунар. конф., посв. 50-летию В.М. Лозовского / под ред. О.В. Лозовской, А.А. Выборнова и Е.В. Долбуновой. СПб.: ИИМК РАН, 2018. С. 72-75.

3. Кузьмина И.Е., Каспаров А.К. Остатки животных из неолитических стоянок Копанище и Черкасская в Воронежской области // Плейстоценовые млекопитающие Северной Евразии. Тр. Зоол. ин-та АН СССР. Т. 168. Л.: Ленуприздат, 1987. С. 87-99.

4. Скоробогатов А.М. Материалы стратифицированной энеолитической стоянки Черкасская-3 на Среднем Дону // Проблемы изучения памятников археологии Восточной Украины. Луганск, 2012. Вып. 3. С. 152-165.

5. Васильева И.Н. К вопросу о гончарных традициях неолитического населения Подонья // Известия СНЦ РАН. 2017. Т. 19, № 3 (2). С. 370-379.

6. Юдин А.И. Варфоломеевская стоянка и неолит степного Поволжья. Саратов: Изд-во Сарат. ун-та, 2004. $200 \mathrm{c}$.
7. Цыбрий В.В. Неолит Нижнего Дона и СевероВосточного Приазовья. Ростов-на-Дону: Издательство СКНЦ ВШ ЮФУ, 2008. 199 с.

8. Цыбрий А.В., Цыбрий В.В., Горлевик А.Ф. «Затянувшаяся путина»: Неолитическое рыболовство и собирательство на Нижнем Дону (по материалам исследований поселения Раздорская II) // Stratum Plus. 2016. № 2. C. 133-174.

9. Выборнов А.А., Кулькова М.А., Ойнонен М., Посснерт Г. Новые радиоуглеродные даты неолитических памятников Подонья // Известия СНЦ РАН. 2017. T. 19, № 3 (2). C. 366-369.

10. Скоробогатов А.М., Смольянинов Р.В., Сурков А.В., Ойнонен М., Посснерт Г. Хронология неолитических памятников лесостепного Подонья // Радиоуглеродная хронология эпохи неолита Восточной Европы VII-III тысячелетия до н.э. / сост. Г.И. Зайцева, О.В. Лозовская, А.А. Выборнов, А.Н. Мазуркевич. Смоленск: Свиток, 2016. С. 244-260.

11. Синюк А.Т. Население бассейна Дона в эпоху неолита. Воронеж: Издательство Воронежского университета, 1986. $180 \mathrm{c}$.

12. Смольянинов Р.В. Ранний неолит Верхнего Дона (по данным керамических комплексов): автореф. дис. ... канд. ист. наук. СПб., 2009. 30 с.

13. Сурков А.В. Стоянка Ивница на р. Воронеж: итоги исследования 2010-2012 гг. // Археологические памятники Восточной Европы. Вып. 15. Воронеж: ВГПУ, 2013. С. 167-186.

\title{
CHERKASSKAYA-5 SITE AND ITS PLACE IN THE EARLY NEOLITHIC ON THE MIDDLE DON RIVER
}

\section{(C) 2018}

Skorobogatov Andrey Mikhailovich, candidate of historical sciences, head of Archeological Department LLC «Terra» (Voronezh, Russian Federation)

\footnotetext{
Abstract. The paper introduces materials of Cherkasskaya-5 site, located on the Middle Don River in the Pavlovsky district of the Voronezh Region. Under the two-meter thickness of the lake-alluvial layers, more than a thousand pieces of finds have been ceramics, stone, bone products and osteology. While analyzing the materials of the monument a ceramic and flint complex of the Early Neolithic appearance have been distinguished (7-6 thousand BC). The received radiocarbon dates, the data of technical and technological analysis and the features of ornamentation, ceramics, the typology of stone and bone inventory, help to find one of the possible ways of Neolithization of the Middle Don, in which the leading role belongs to the steppe component. Paleozoological analysis showed that the osteological collection is dominated by the bones of birds (64,4\% of all bones), there are mammals $(21,8 \%)$, fish $(9,7 \%)$, turtle marsh $(4,1 \%)$. Among domestic mammals domestic species (dog, horse, pig, sheep) are identified. However, the presence of late Neolithic and Eneolithic (srednedonskaya, dnepro-donetskaya, nizhnedonskaya, and srednestogovskaya cultures) in the ceramics layer leaves open the question of the domestic animal species belonging to the early Neolithic. The material of the site makes it possible to characterize this place as a series of seasonal short-term specialized sites intended for conducting network fishing, hunting for waterfowl, catching turtles and collecting shellfish as well as for processing the products of fishing and hunting in the Neolithic age.

Keywords: Middle Don; Bityug river; Voronezh Region; forest-steppe; excavations; site; stratigraphy; ceramics; stone and bone products; radiocarbon dates; early Neolithic; steppe tradition; pencil-drawn ornamentation; orlovskaya culture; hunting; fishing; sinker; gathering; domestic animals.
}

\section{КАМЕННАЯ ИНДУСТРИЯ РАННЕГО НЕОЛИТА ВЕРХНЕГО ДОНА}

Смольянинов Роман Викторович, кандидат исторических наук, заведующий кабинетом археологии и этнологии

Юркина Елизавета Сергеевна, старший лаборант кафедры отечественной и всеобщей истории Липеикий государственный педагогический университет имени П.П. Семенова-Тян-Шанского (2. Липеик, Российская Федерация)

Аннотащия. Практически все пойменные поселения бассейна р. Дон и его притоков являются многослойными. До последнего времени говорить о каменной индустрии раннего неолита Верхнего Дона не представ- 
лялось возможным. Все выводы о материальном производстве ранненеолитического населения этой территории были сделаны А.Т. Синюком по среднедонским стоянкам. Он характеризовал каменную индустрию производства орудий как пластинчатую. В данной статье упоминаются наиболее важные стоянки и даётся обзор современного состояния изучения каменной индустрия раннего неолита Верхнего Дона. На сегодняшний день мы выделяем на Верхнем Дону материалы четырёх ранненеолитических культур: среднедонской (72 памятника), карамышевской (26 памятников), верхневолжской (4 памятника) и елшанской (4 памятника). Самые ранние материалы этих культур на исследуемой территории датируются VI тыс. до н.э. (CalBC). Данные по каменной индустрии населения, оставившего керамику елшанской и верхневолжской культур на поселениях Верхнего Дона, пока отсутствуют. Выявлены каменные коллекции, которые можно связать только со среднедонской и карамышевской раненнеолитическими культурами. Каменную индустрию их можно охарактеризовать как отщеповую.

Ключевые слова: лесостепь; ранний неолит; кремень; кварцит; среднедонская неолитическая культура; карамышевская неолитическая культура; Верхний Дон; орудие; отщеп; раскоп; стоянка; наконечник; скребок; нож; многофункциональное орудие; пластина; нуклеус; типологический анализ; радиоуглеродная дата.

Лесостепное Подонье располагается на территории Верхнего и Среднего течения р. Дон с его притоками, в том числе и тех, устья которых располагаются уже в рамках степной зоны. Река Дон на всем своем протяжении протекает с севера на юг.

Бассейн Верхнего Дона на современной территории Российской Федерации преимущественно находится в Липецкой, Тульской и Воронежской областях.

В лесостепном Подонье в 1971 году была выделена А.Т. Синюком ранненеолитическая среднедонская культура [1], а его полное представление о ней было сформировано в монографии 1986 года - «Население бассейна Дона в эпоху неолита» [2]. При этом все выводы о материальном производстве ранненеолитического населения, в том числе и Верхнего Дона, были сделаны по среднедонским (Монастырская 1, Копанище 1 и 2, Дармодехинская, Черкасская, Дронихинская) и находящимся на пограничье Среднего и Верхнего Дона кусту Университетских стоянок. Главным критерием обозначения ранненеолитических памятников исследуемого региона вплоть до сегодняшнего дня, даже в тех случаях, когда комплекс кремнёвого инвентаря ничем не отличается от набора орудий мезолитической эпохи, является наличие керамической лепной обожженной посуды. Комплекс каменных орудий раннего неолита А.Т. Синюк оценивал как пластинчатый.

На сегодняшний день, в отличие от территории Среднего Дона, благодаря накоплению в последние два десятилетия новых данных, мы выделяем на Верхнем Дону материалы четырёх ранненеолитических культур: среднедонской (72 памятника), карамышевской (26 памятников), верхневолжской (4 памятника) и елшанской (4 памятника). Самые ранние материалы этих культур на исследуемой территории датируются по керамике VI тыс. до н.э. (CalBC) [3]. Данные по каменной индустрии населения, оставившего керамику елшанской и верхневолжской культур на поселениях Верхнего Дона, пока отсутствуют. Выявлены каменные коллекции, которые можно связать только со среднедонской и карамышевской раненнеолитическими культурами.

\section{Источники}

1. Стоянка карамышевской культуры Ступино. В 2014 г. обследовалась А.В. Сурковым на площади $42 \mathrm{M}^{2}$ [4]. Она находится на пойменном останце левого берега p. Воронеж на южной окраине одноименного села Рамонского района Воронежской области (рис. 1:5).
В раскопе обнаружено всего 126 каменных предметов, преимущественно из разноцветного карбонового (88 ед.) и мелового кремня (24 ед.). Подавляющая их часть залегала в нижнем слое светлой супеси, поэтому в целом данная коллекция может соотноситься с карамышевской культурой. Под вопросом ранний возраст наконечника стрелы (рис. 2: 9).

Среди находок из карбонового кремня, в основном желто-коричневых и красных оттенков, преобладают отходы производства - 52 отщепа и скола (из них 9 с ретушью), 8 чешуек, галька. Нуклеусы в количестве семи экземпляров имеют аморфную форму, предельно утилизированы и служили для снятия небольших отщепов. Среди орудий выделяются 10 скребков (рис. 2: 6-8), скобель (рис. 2: 11), обломок черешковой части наконечника стрелы. Пластин и их сечений только восемь (рис. 2: 2-3), края пластин имеют следы утилизации в виде нерегулярной ретуши. Один из скребков реутилизирован в резец (рис. 2: 10). Одна из галек использовалась в качестве отбойника. Из мелового кремня половина является отходами производства, шесть пластин и их сечений (рис. 2: 4), по одному скребок, скобель, перфоратор, резец и наконечник стрелы, двустороннеобработанный струйчатой ретушью с выделенным массивным черешком (рис. 2: 9).

Помимо этого в раскопе обнаружено восемь предметов из кварцита: пластина с ретушью (рис. 2: 5), два медиальных сечения, оставшиеся - отщепы, скол и чешуйка. Из мягких пород камня только шесть предметов. Интересно обнаружение своеобразного «клада» - на зачистке по материку компактно лежали обломок лезвийной части сланцевого тесла (рис. 2: 1) и два отбойника из кварцевой гальки и пришлифованного песчаника. Остальные предметы данной группы (песчаник, гранит и железняк) фрагментированы, их поверхности были пришлифованы. В целом каменный инвентарь характеризуется выраженным отщеповым характером (среди карбонового кремня 9\% пластин и сечений) и предельным использованием нуклеусов. Отходы производства составляют чуть более половины находок.

По мнению автора раскопок А.В. Суркова, ценность данной коллекции заключается в возможности ее использования для характеристики инвентаря карамышевской культуры в целом, поскольку изделия из камня на верхнедонских неолитических стоянках малочисленны, а установить их связь с конкретной археологической культурой на многослойных памятниках не представляется возможным. 


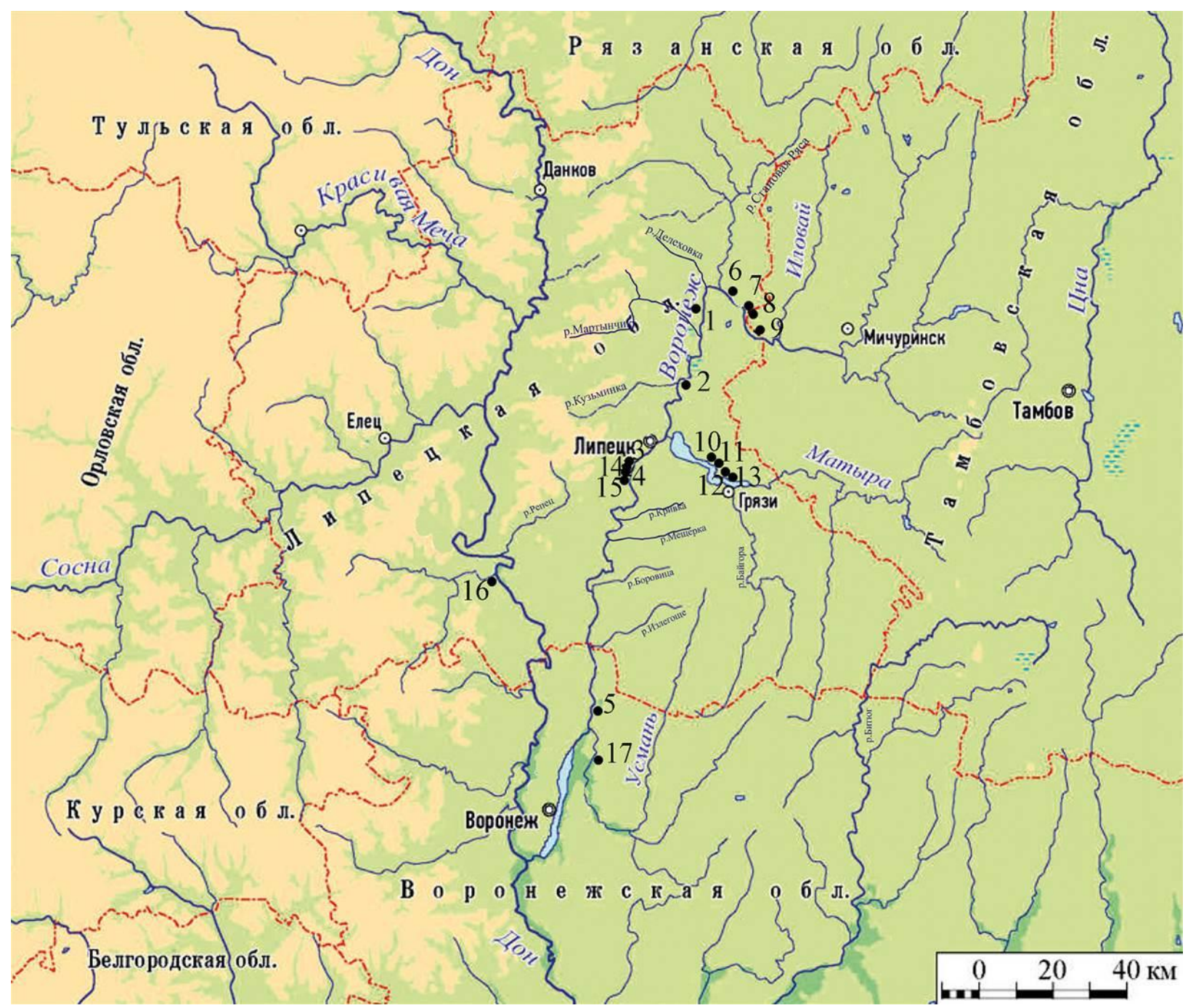

Рисунок 1 - Карта ранненеолитических памятников, упоминаемых в статье.

1- Доброе 9; 2- Капитанщино 7; 3- Карамышево 5; 4- Карамышево 1; 5- Ступино;

6-Васильевский Кордон 3; 7- Васильевский Кордон 5; 8- Васильевский Кордон 7;

9 - Васильевский Кордон 1; 10 - Рыбное Озеро I. Пункт 201; 11- Рыбное Озеро II. Пункт 202;

12 - Ярлуковская Протока. Пункт 242; 13 - Ярлуковская Протока. Пункт 222;

14- Карамышево 9; 15 - Карамышево 19; 16- Ксизово 6; 17-Университетская 3

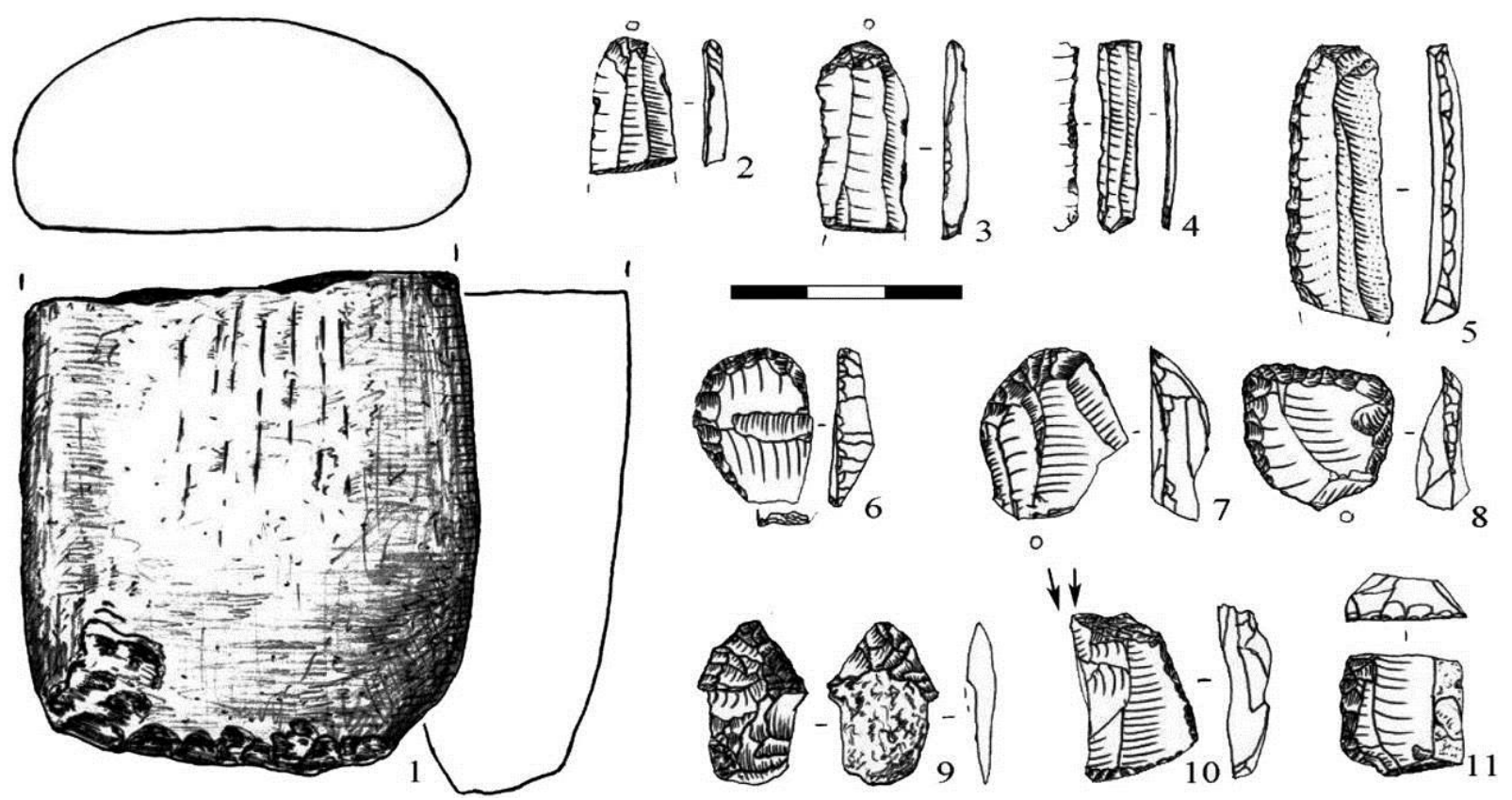

Рисунок 2 - Стоянка Ступино. 1-11 - изделия из камня карамышевской культуры (по: [4]) 
2. Поселение карамышевской культуры Карамышево 5 (рис. 1: 4). Оно находится на пойменном останце первой террасы р. Воронеж, возле её старицы, в Грязинского районе Липецкой области в черте с. Карамышево. Исследованная площадь памятника составила 64 м² $\left.^{2} 5 ; 6\right]$. Изделия из камня представлены одним наконечником стрелы треугольной формы с черешком (рис. 3: 6), одним скобелем (рис. 3: 9), тремя дисковидными нуклеусами для снятия отщепов (рис. 3: 10), двумя ножами на крупных отщепах (рис. 3: 1, 3), одним отбойником, пятью скребками (рис. 3: 2, 4, 5, 8, 11) и двумя резцами (рис. 3: 7). Также в качестве скребков могли использоваться четыре ретушированных отщепа. Ведущий материал местный низкокачественный кремень серого цвета. Один скребок изготовлен из кварцита. Вероятнее всего, практически все изделия из камня можно датировать неолитической эпохой. В раскопе выявлены единичные фрагменты среднестоговской, катакомбной и воронежской культур. На 96 кремнёвых находок приходится только две неправильных пластины [6].

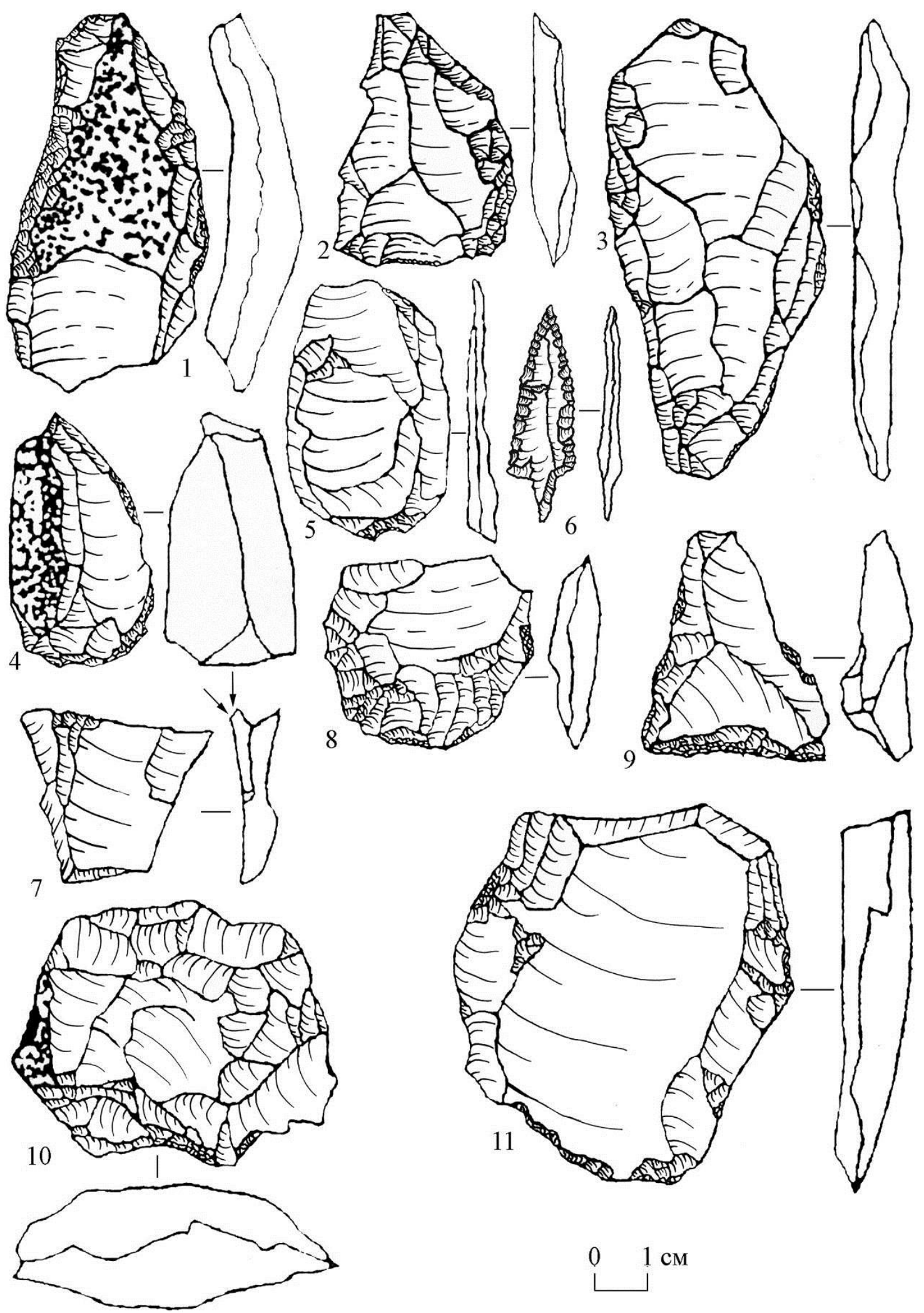

Рисунок 3 - Каменный инвентарь поселения Карамышево 5. 1-11- орудия из кремня 
3. Многослойное поселение Карамышево 1 (рис. 1: 3). Оно находится в границах одноимённого села на левом берегу р. Воронеж. Памятник обнаружен в 1964 году В.П. Левенком. На поселении в 2001 году общей площадью $320 \mathrm{M}^{2}$ [7; 8] был заложен раскоп.

Мы считаем возможным использовать кремнёвую коллекцию этого поселения для анализа и полагаем, что она в подавляющем своём большинстве относится к карамышевской культуре. В материалах памятника, единственном на Верхнем Дону, выделяется коллекция изделий из чёрного мелового кремня месторождений Среднего Дона. Для памятников Верхнего Дона льяловской неолитической культуры и репинской ранней бронзы, незначительное количество керамики которых также обнаруженных здесь, не характерно использование кремня подобного типа. Также стратиграфически кремнёвые артефакты залегали вместе с керамикой карамышевской культуры в предматериковом слое.

На памятнике обнаружены фрагменты пяти сосудов карамышевской культуры [7]. По используемому сырью для изготовления орудий кремнёвую коллекцию (всего 64 предмета) поселения Карамышево 1 можно разделить на две части. Из чёрного мелового кремня всего обнаружено 35 кремнёвых находок. Нами выявлено: пять пластин (четыре с треугольным сечением (рис. 4: 4-6, 8, 9), одна - с трапециевидным (рис. 4: 7), 16 аморфных отщепов, два нуклевидных обломка, на одном из которых обнаружены следы утилизации, один наконечник треугольной формы на пластине с прямым основанием и с приостряющей ретушью с одной стороны - по всем граням, кроме основания, а с другой - только по кончику (рис. 4: 17), два торцевых скребка на пластинах (рис. 4: 1415), две проколки (рис. 4: 2, 3), один нож на отщепе (рис. 4: 10), два концевых скребка, изготовленных на отщепах (рис. 4: 19-20), три скребка обработанных ретушью по всем своим граням (рис. 4: 13, 18). Кроме трёх отщепов из кварцита, все остальные 26 кремнёвых орудий и отходов их производства, изготовлены из цветного валунного, местного, плохого качества кремня. Было также обнаружено 18 отщепов, один из них с ретушью, очень сильно сработанный аморфной формы нуклеус, скребок, нуклевидный обломок, с противолежащей на гранях ретушью (рис. 4: 12), скобель (рис. 4: 22), обломок скребка с крутой ретушью (рис. 4: 21), проколка (рис. 4: 1), два наконечника, один из которых треугольной формы с усечённым его основанием (рис. 4: 11), второй - треугольной формы с черешком, ретушированный по всей поверхности, как снаружи, так и изнутри [7].

4. Поселение среднедонской культуры Доброе 9. В 2014 году А.А. Клюкойть в размывах берега p. Воронеж обнаружил ранненеолитическую керамику у южной окраины с. Доброе Липецкой области (рис. $1: 1$ ) на пойменном останце высотой 2 м над рекой. В разведочном шурфе стоянки Доброе 9 площадью $4 \mathrm{~m}^{2}$ им был выявлен культурный слой с 11 фрагментами керамики среднедонской неолитической культуры и одной костью животного [9].

В 2017 году на разрушающемся участке А.А. Куличковым был заложен раскоп площадью $20 \mathrm{~m}^{2}$ [10].
На памятнике прослеживается четкая стратиграфия, и впервые за 46 лет с момента выделения А.Т. Синюком среднедонской неолитической культуры [1] был выявлен на территории Верхнего Подонья не смешанный культурный слой, вмещающий в себя керамику, кости животных, изделия из камня. Обнаружено 349 фрагментов керамики среднедонской культуры, 33 каменных находки и 37 фрагментов костей.

Каменная часть коллекция содержит 33 единицы, из которых 16 - орудия. Основное количество артефактов изготовлено из местного мелового кремня различных цветовых оттенков, в меньшей степени фиксируется галечный кремень, в единичных случаях - песчаник и кварцитопесчаник.

Продукты первичного расщепления представлены двумя нуклеусами. Один из них многоплощадочный аморфной формы (рис. 6: 2), второй - одноплощадочный уплощенной призматической формы, покрытый с одной стороны коркой (рис. 5: 5). Их использование было направлено на получение отщепов. Пластинчатая индустрия на памятнике отсутствует, выявлен только один пластинчатый отщеп со следами незначительной утилизации (рис. 5: 3).

При всей малочисленности коллекции, орудийный набор памятника представлен достаточно широко:

- одним наконечником треугольной формы с резко выраженными асимметричными шипами и обломанным черешком, обработанный двусторонней отжимной ретушью (рис. 5: 10). Со стороны спинки и брюшка наблюдаются следы патинизации белого цвета. Ближайшая аналогия подобного типа наконечников встречена в материалах памятников Среднего Дона: Черкасской стоянки [11, с. 169] и стоянки Дрониха [2, с. 112] на р. Битюг;

- одним угловым резцом (рис. 5: 1) на среднем по величине отщепе, на сколе которого прослеживается дополнительная подработка;

- одним ножом (рис. 5: 7) на крупном отщепе подтреугольной формы;

- одним концевым скребком с прямым лезвием, $2 / 3$ изделия которого по краям обработаны притупляющей ретушью (рис. 6: 5);

- двумя проколками на отщепах (рис. 5: 4; рис. 6: 10). Вероятно, функции перфоратора выполнял ещё один пластинчатый отщеп (рис. 5: 2), на котором визуально прослеживается на конце изделия приостряющая ретушь.

Кроме того, обнаружено шесть полифункциональных орудий, сочетавших в себе несколько рабочих функций: по два - ретушер-струг (рис. 5: 8), скребок-нож (рис. 6: 9), резец-скобель (рис. 6: 4), и по три: скребок-ретушер-провертка (рис. 6: 7), проколка-ретушёр-скребок (рис. 6: 7), резчик-проколкаструг (рис. 6: 8).

Обнаружено также два фрагмента шлифовальных плит. Одна из песчаника (рис. 6: 3) размером 8,7 см в длину, 8 см в ширину и до 1,4 см в толщину, рабочие поверхности которой неровные и со следами эпизодической шлифовки. Вторая - из кварцитопесчаника (рис. 6: 1) в длину 9,3 см, в ширину 8 см, в толщину 
Смольянинов Р.В., Юркина Е.С.

Каменная индустрия раннего неолита Верхнего Дона

07.00.00 - исторические науки и археология

до 1,6 см; на обеих сторонах изделия имеется однородная зашлифованная рабочая поверхность. В единичном экземпляре выделен обломок кремня со следами бифасиального скалывания (рис. 6: 9). Оставшаяся часть находок 14 экземпляров - отходы производства: обломки кремня и отщепы, на пяти из которых визуально прослеживаются следы утилизации.

Отметим, что одноплощадочный нуклеус, обломок кремня со следами бифасиального скалывания, нож, ретушер-струг, проколка на пластине, наконечник, резец и фрагменты шлифовальных плит залегали в горизонте с нивелировочными отметками $150 \ldots-181$ см (до уровня песчаного материка). Судя по стратиграфическим и планиграфическим наблюдениям, на памятнике данный набор орудий можно соотнести с керамической коллекцией среднедонской неолитической культуры.
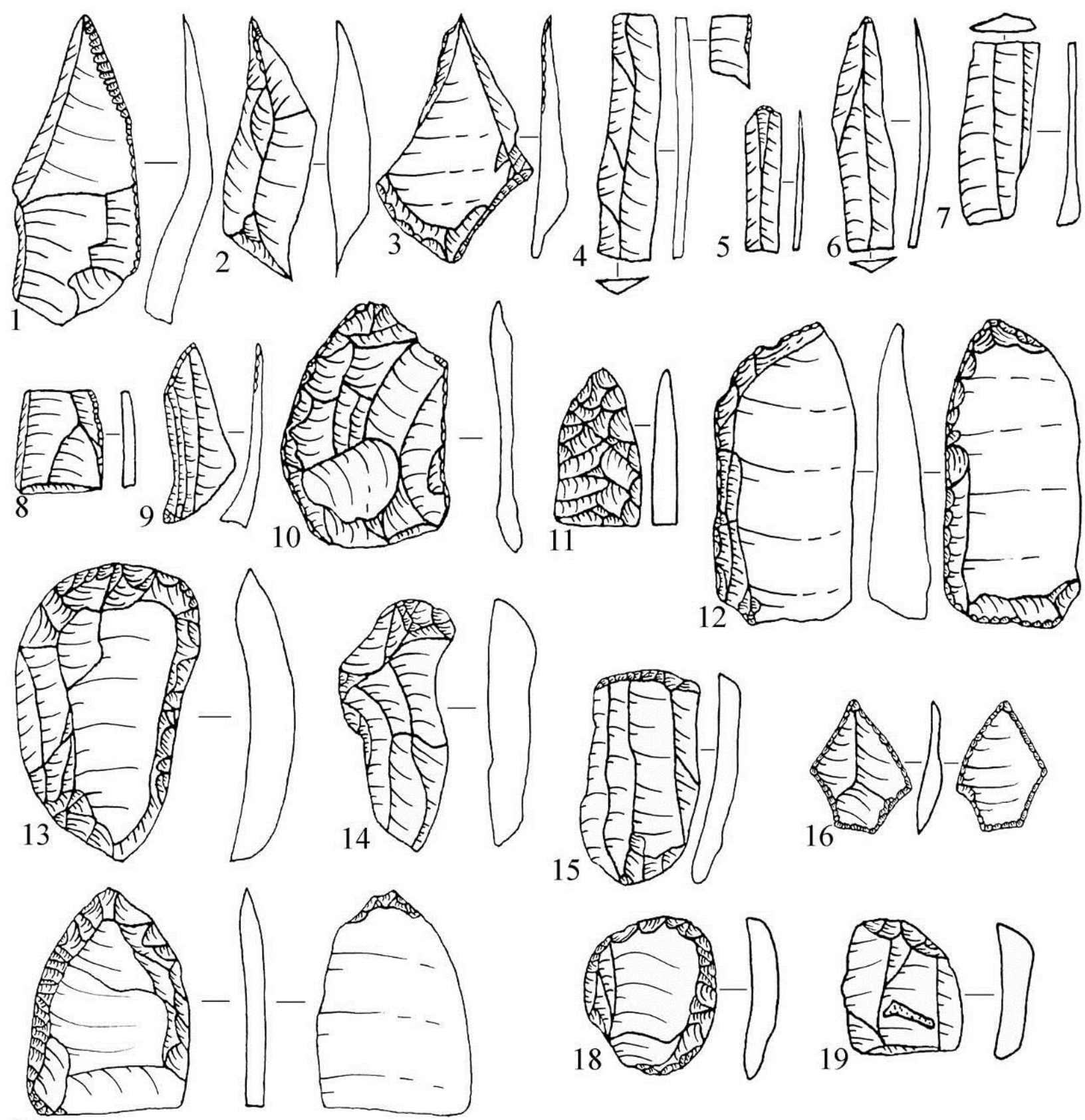

15
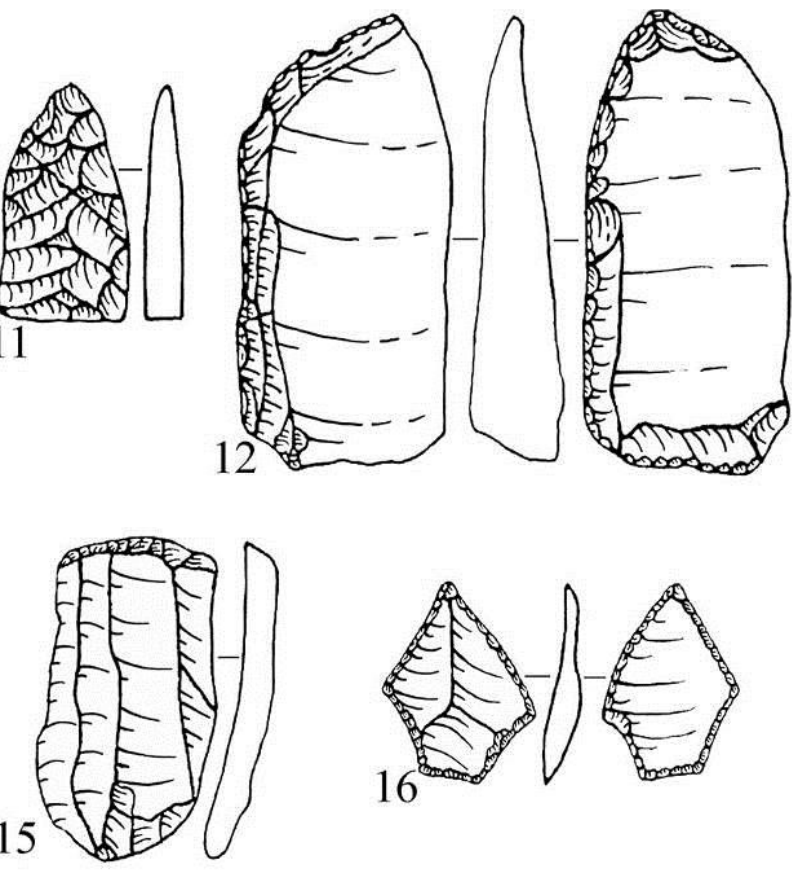

17
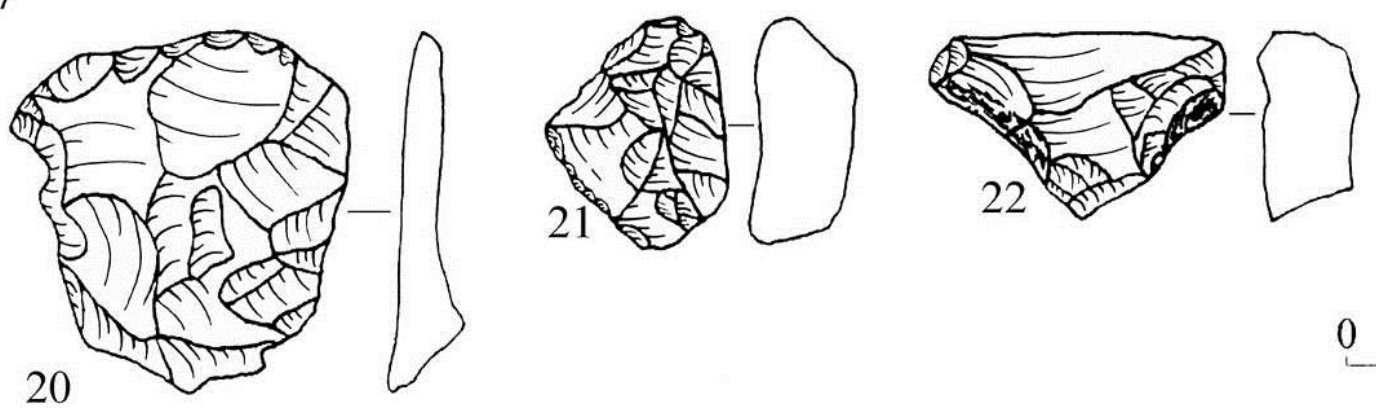

0
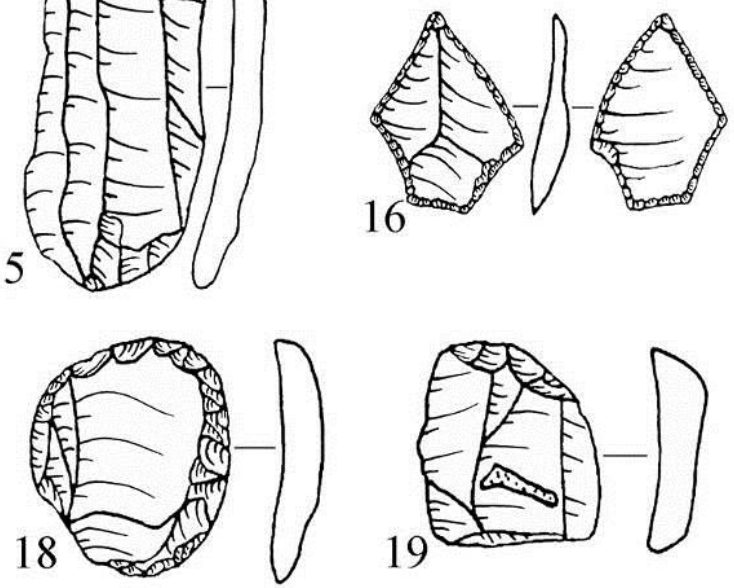

Рисунок 4 - Каменный инвентарь поселения Карамышево 1.

1-22 - орудия из кремня 
Смольянинов Р.В., Юркина Е.С.

5. Поселение среднедонской культуры Капитанщино 7. Находится в Добровском районе Липецкой области к северо-западу от с. Капитанщино (рис. 1: 2). Открыто Т.В. Смольяниновой в 2016 году [12]. Памятник многослойный. В двух разведочных шурфах $\left(8 \mathrm{~m}^{2}\right)$ культурам, которые использовали каменные орудия, принадлежали материалы среднедонской и льяловской (одна стенка сосуда) керамических традиций. Поэтому с высокой долей уверенности каменные находки можно отнести к среднедонской неолитической культуре. Всего обнаружено 30 предметов, что составляет $37,5 \%$ от общей коллекции.
Скребки представлены тремя экземплярами, все они концевые, однолезвийные, подокруглой формы с ретушью на боковой стороне. Два из них изготовлены из кремня (рис. 7: 7), один из кварцита (рис. 7: 3). Проколка представлена одним экземпляром (рис. 7: 6). Она изготовлена на отщепе из черного мелового кремня из месторождений Среднего Дона. Скобель в коллекции также один (рис. 7: 10) и изготовлен из низкокачественного цветного кремня на торце пластинчатого отщепа, которого визуально прослеживаются две скоблевидные выемки.
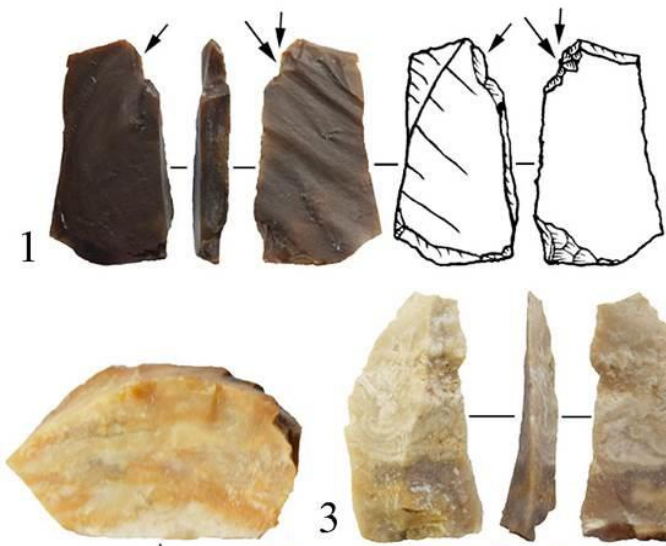

3
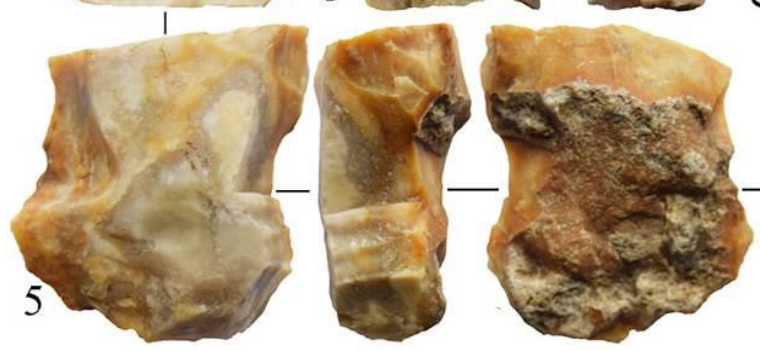

2
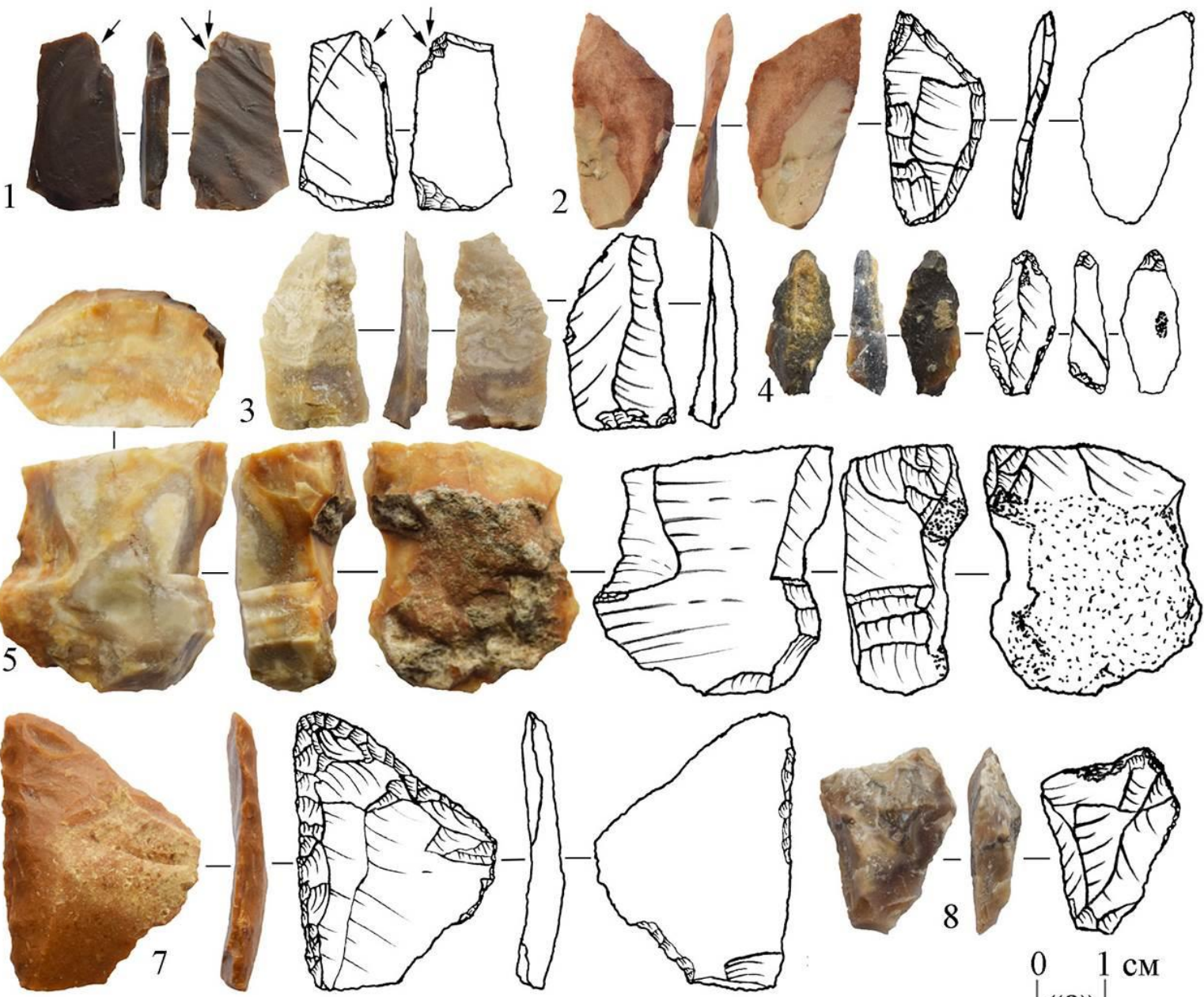

$0 \quad 1 \mathrm{~cm}$

〈a»»
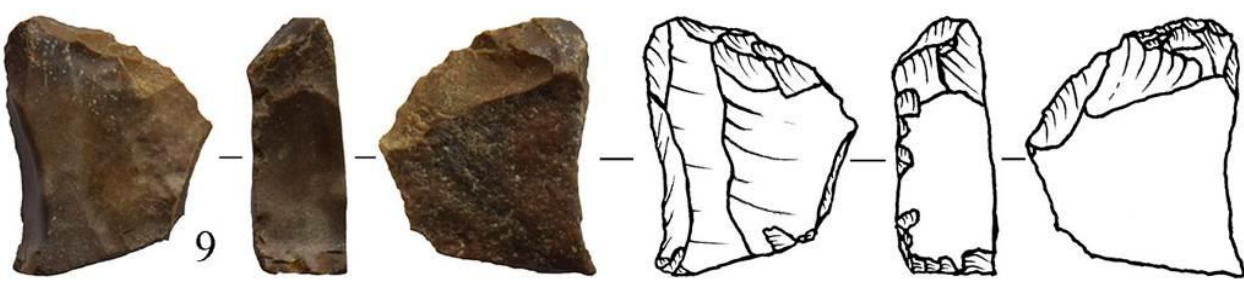

$0 \quad 1 \mathrm{~cm}$
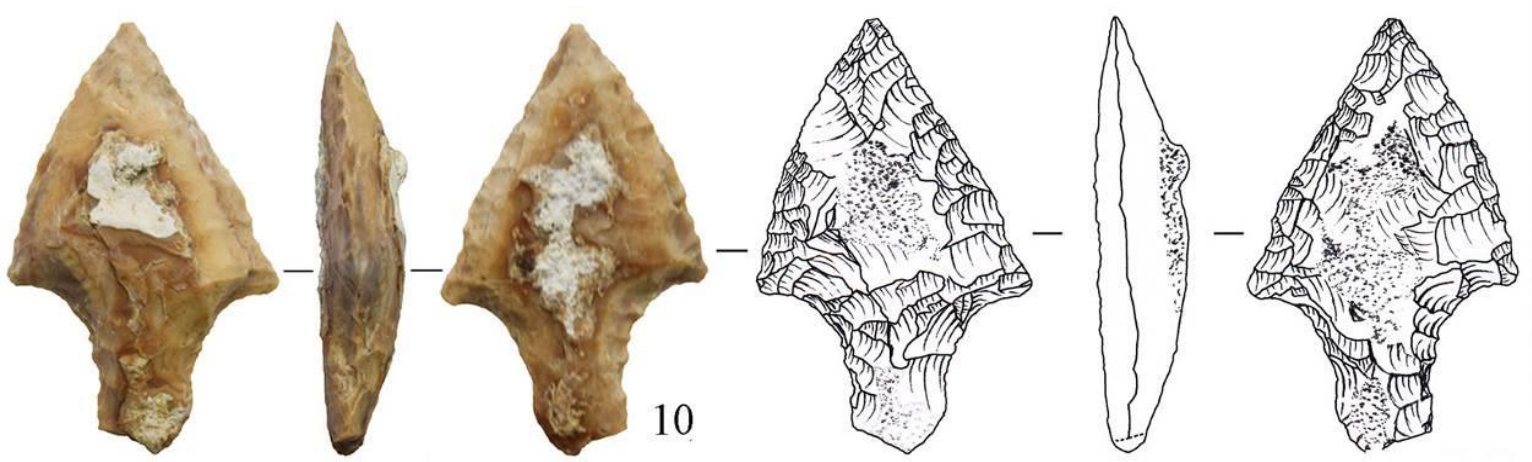

Рисунок 5 - Каменный инвентарь стоянки Доброе 9. 1-9- масштаб «а», 10- масштаб «б» 
Нуклеусы для скалывания отщепов представлены тремя экземплярами (рис. 7: 1, 2, 5), два из которых одноплощадочные, один призматической формы, а второй аморфной. Третий клиновидный нуклеус имеет две ударные площадки. Все они изготовленные на узких кремнёвых плитках.

Остальные находки представлены 13 отщепами, одним кремневым обломком, двумя пластинчатыми отщепами (рис. 7: 8,11 ) и одной миниатюрной пластиной из черного мелового высококачественного кремня (рис. 7: 4).

6. Поселение среднедонской культуры Рыбное Озеро 1 (пункт 201). Располагается на правом берегу p. Матыра (левый приток р. Воронеж). Выявлены материалы среднедонской культуры от двух-трёх сосудов [13-20]. Всего по два фрагмента керамики раннего этапа льяловской культуры и дронихинского типа и приходится на каждые 50 фрагментов керамики среднедонской культуры (практически отсутствует посуда других археологических культур). Были выявлены 40 находок из камня. К орудиям относятся отбойник, два обломка скребка, один обломок наконечника иволистной формы с усеченным основанием (рис. 7: 13). Также обнаружены две пластины (рис. 7: 9, 12).
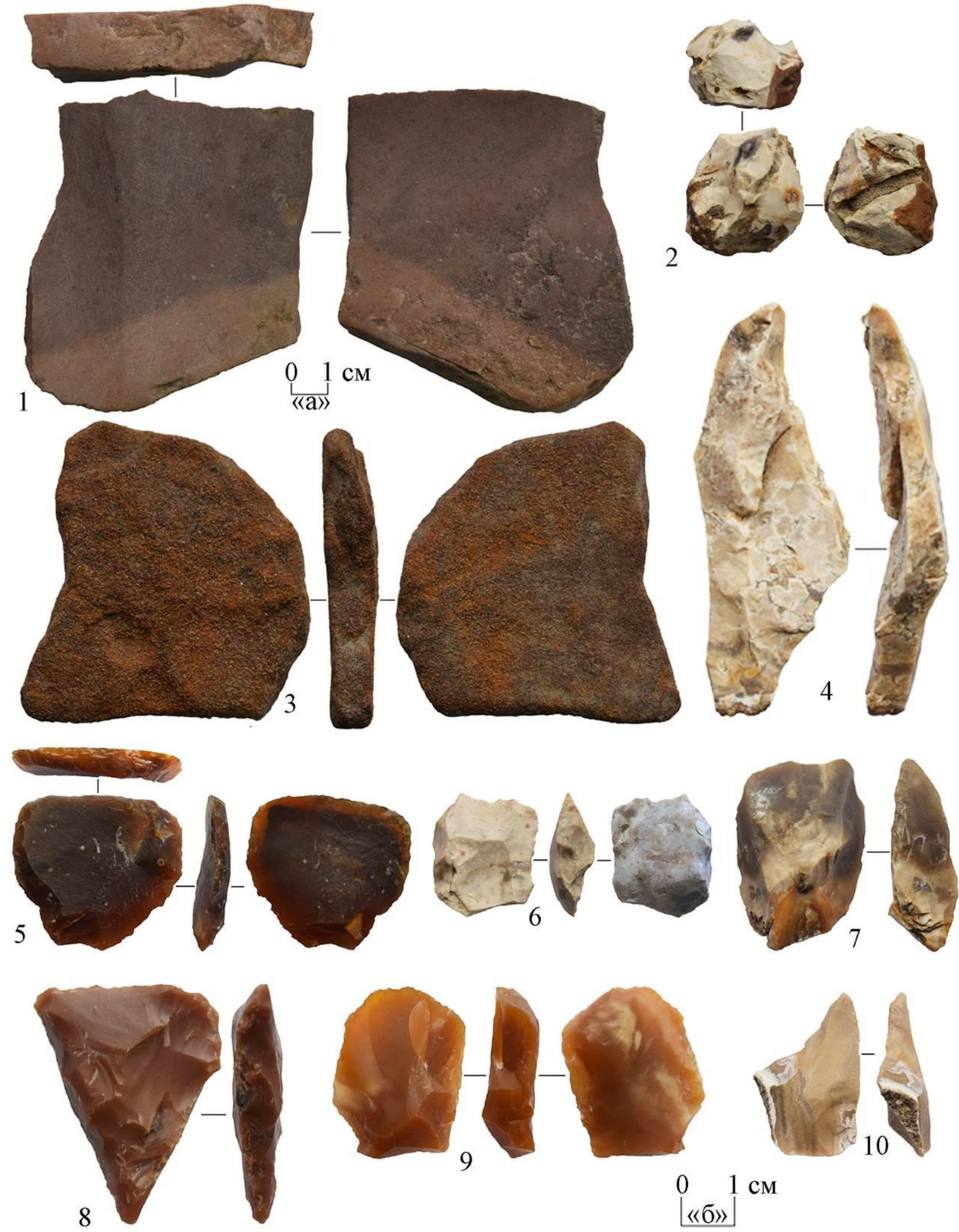

\section{$0 \quad 1 \mathrm{~cm}$ \\ «б»}

Рисунок 6 - Каменный инвентарь стоянки Доброе 9. 1, 3- масштаб «а», 2, 4-10- масштаб «б» 

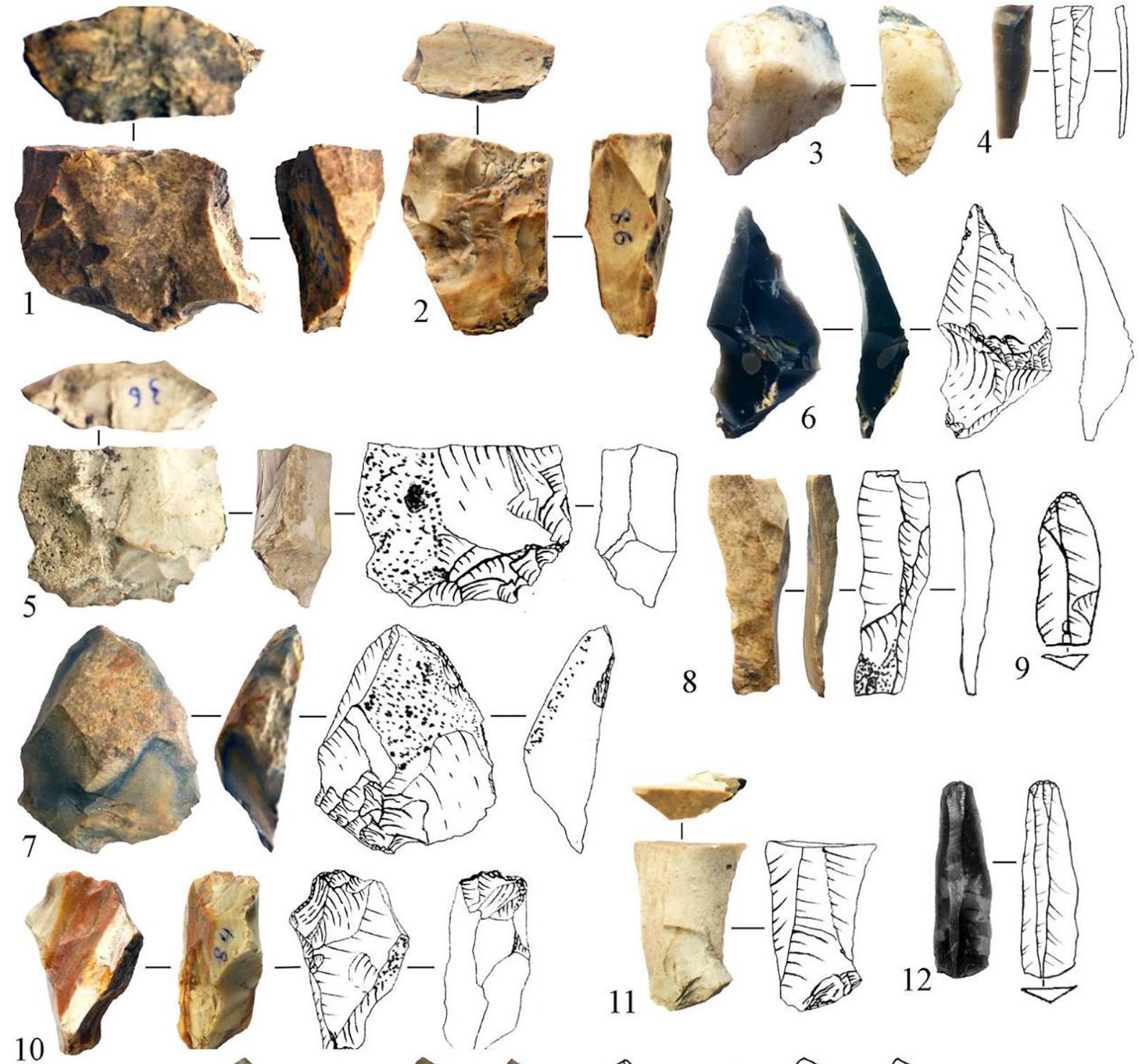

10

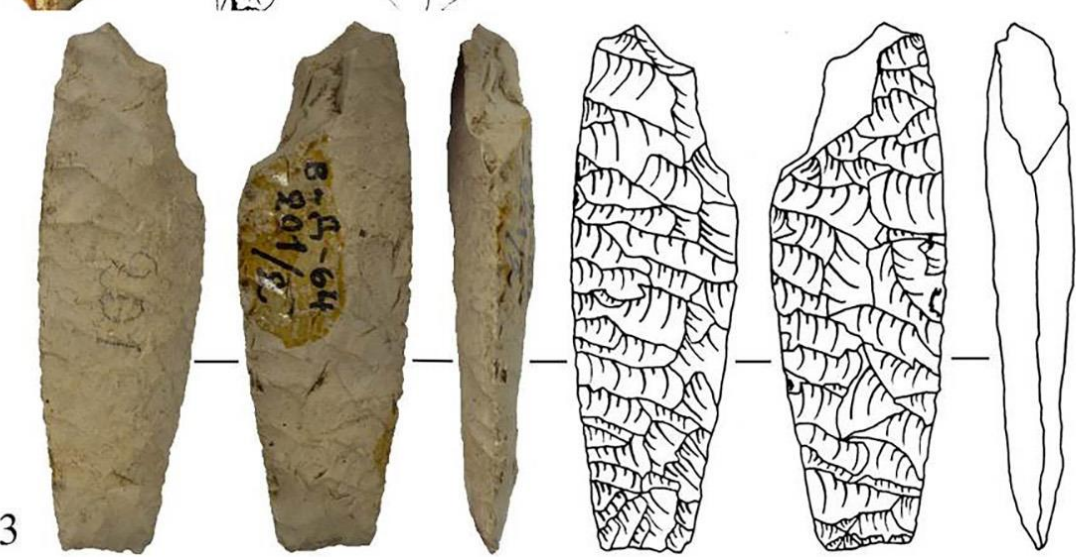

Рисунок 7 - Каменный инвентарь поселения Капитанщино 7 и стоянки Рыбное Озеро I (Пункт 201). 1-8, 10-11- Капитанщино 7; 9, 12, 13- Рыбное Озеро I

\section{Bыводы}

Традиционно основным признаком каменного инвентаря раннего неолита в лесостепном Подонье, в частности среднедонской неолитической культуры, А.Т. Синюком назывался пластинчатый облик производства и подавляющее преобладание орудий на пластинах, а также констатировалось отсутствие резцов [2, с. 62-65]. Кремнёвые коллекции памятников, которые мы связываем с ранненеолитическим возрастом на Верхнем Дону, этим выводам полностью противоречат. На стоянках с материалами как карамышевской, так и среднедонской неолитических ку- льтур доминирует ярко выраженная отщеповая технология изготовления орудий. Помимо тех коллекций каменных орудий, которые мы однозначно связываем с ранненеолитическим возрастом: Ступино, Карамышево 1, 5, Доброе 9, Капитанщино 7, Рыбное Озеро 1 (пункт 201), - данный вывод косвенно подтверждает и наша статистическая таблица 1. Она вполне корректна для понимания характера кремнёвого производства раннего неолита. Мы можем наблюдать крайне малое количество пластин, орудий, изготовленных из них, изделий, связанных с их производством, среди общей массы каменных артефактов стоянок на Верхнем Дону. 
Таблица 1 - Количество пластин, орудий, изготовленных из них, и изделий, связанных с их производством, среди общей массы каменных артефактов основных стоянок Верхнего Дона

\begin{tabular}{|l|c|c|c|c|c|c|}
\hline \multicolumn{1}{|c|}{ Название памятника } & $\begin{array}{c}\text { Кол-во } \\
\text { каменных } \\
\text { находок }\end{array}$ & $\begin{array}{c}\text { Вскрытая } \\
\text { площадь } \\
\text { памятника, } \mathbf{2}^{2}\end{array}$ & $\begin{array}{c}\text { Кол-во } \\
\text { ору- } \\
\text { дий }\end{array}$ & $\begin{array}{c}\text { Кол-во } \\
\text { пла- } \\
\text { стин }\end{array}$ & $\begin{array}{c}\text { Кол-во } \\
\text { орудий на } \\
\text { пластинах }\end{array}$ & $\begin{array}{c}\text { Нуклеусы } \\
\text { сля производ- }\end{array}$ \\
\hline Карамышево 1 & 69 & 320 & 25 & 6 & 1 & $7 /(-)$ \\
\hline Карамышево 5 & 96 & 64 & 12 & 2 & - & $3 /(-)$ \\
\hline Карамышево 9 & 980 & 724 & 196 & 70 & 19 & $46 /(5)$ \\
\hline Карамышево 19 & 103 & 74 & 17 & 8 & 1 & $9 /(2)$ \\
\hline Ксизово 6 & 891 & 253 & 277 & 23 & 5 & $21 /(-)$ \\
\hline Васильевский Кордон 1 & 466 & 242 & 108 & - & 1 & $13 /(1)$ \\
\hline Васильевский Кордон 3 & 3 & 84 & - & - & - & - \\
\hline Васильевский Кордон 5 & 318 & 183 & 58 & 7 & 2 & $8 /(4)$ \\
\hline Васильевский Кордон 7 & 1030 & 141 & 212 & 31 & 5 & $94 /(7)$ \\
\hline Рыбное Озеро 1. Пункт 201 & 40 & 150 & 6 & 2 & - & - \\
\hline Рыбное Озеро 2. Пункт 201 & 50 & 200 & 8 & - & - & $1 /(-)$ \\
\hline Ярлуковская Протока. Пункт 222 & 304 & 600 & 35 & 10 & 1 & $6 /(1)$ \\
\hline Ярлуковская Протока. Пункт 242 & 98 & $>45$ & 17 & 1 & 1 & $5 /(-)$ \\
\hline Доброе 9 & 33 & 24 & 16 & - & - & $2 /(1)$ \\
\hline Капитанщино 7 & 30 & 8 & 5 & 1 & - & $3 /(-)$ \\
\hline Ступино & 126 & 42 & 19 & 16 & 1 & $7 /(-)$ \\
\hline Университетская 3 & 265 & 1576 & 149 & 12 & 16 & $13 /(3)$ \\
\hline
\end{tabular}

В рассмотренных нами каменных коллекциях также было отмечено несколько характерных черт:

- статистические данные иллюстрируют яркое преобладание отщеповой технологии над пластинчатой на территории Верхнего Подонья. Очень низок процент нуклеусов именно для скалывания пластин;

- обращает на себя внимание тот факт, что преобладающая часть пластин из чёрного высококачественного мелового кремня не местного происхождения и имеет миниатюрные размеры, тогда как кварцитовые пластины, наоборот, крупные или средние по величине;

- с определённой уверенностью можно говорить, что пластины из многослойных верхнедонских стоянок, изготовленные из чёрного качественного кремня среднедонских месторождений, имеют ранненеолитический возраст;

- представленные в коллекциях орудия не образуют устойчивых серий и очень неоднородны по своему типологическому облику;

- на каждом памятнике есть шлифовальные камни из песчаника или кварцитопесчаника с обширными участками рабочих поверхностей, однако процент шлифованных изделий не представителен;

- встречаются единичные резцы;

- в культурных слоях ранненеолитических памятников на Верхнем Дону встречается крайне малое количество каменных артефактов, что частично свидетельствует о высоком уровне заменяющих их производств - косторезного и деревообрабатывающего.

\section{Список литературы:}

1. Синюк А.Т. Памятники неолита и энеолита на Среднем Дону: автореф. дис. ... канд. ист. наук. Воронеж, 1971. $14 \mathrm{c}$.

2. Синюк А.Т. Население бассейна Дона в эпоху неолита. Воронеж: Издательство Воронежского государственного университета, 1986. 179 с.

3. Smolyaninov R., Skorobogatov A., Surkov A. Chronology of Neolithic sites in the forest steppe area of the Don River // Documenta Praehistorica. XLIV. Ljubljana, 2017. P. 192-202.

4. Сурков А.В. Стоянка Ступино - новый ранненеолитический памятник на Верхнем Дону // Тверской археологический сборник. Вып. 10. Тверь: Издательство Триада, 2015. С. 168-173.

5. Смольянинов Р.В. Отчет к открытым листам № 452 и № 891 об исследованиях многослойных поселений Карамышево 9 и Карамышево 5 у с. Карамышево в Грязинском районе Липецкой области в 2002 году. Архив ИА РАН. Ф. 1. Р-1. № 27676.

6. Смольянинов Р.В. Карамышево 5 - ранненеолитическое поселение нового типа на территории Верхнего Дона // Чтения, посвящённые 100-летию деятельности в ГИМ В.А. Городцова: тез. конф. Ч. 1. М.: Отдел типографских работ ГИМ, 2003. С. 49-51.

7. Чивилёв В.А. Отчет об археологических исследованиях в 2001 г. Архив ИА РАН. Ф. 1. Р-1.

8. Смольянинов Р.В., Чивилёв В.А. Материалы эпохи неолита - энеолита с многослойного поселения Карамышево 1 на р. Воронеж // Верхнедонской археологический сборник. Вып. 3. Липецк-СПб.: РИЦ ЛГПУ, 2007. С. 91-98.

9. Клюкойть А.А. Отчёт о проведении разведочных работ в среднем течении р. Воронеж на территории Добровского, Грязинского и Липецкого районов Липецкой области в 2014 году // Архив ИА РАН. Р-1.

10. Куличков А.А. Отчёт о проведении разведочных исследований в бассейне р. Воронеж в пределах Добровского района Липецкой области, Мичуринского района Тамбовской области в 2017 году // Аpхив ИА РАН. Ф. 1. Р-1.

11. Скоробогатов А.М. Черкасская стоянка в Среднем Подонье. Результаты исследований 20092010 гг. // Тверской археологический сборник. Вып. 11. Тверь: Издательство «Триада», 2018. С. 161-195.

12. Смольянинова Т.В. Отчет о проведении разведочных исследований в Добровском районе Липецкой области в 2016 году // Архив ИА РАН. Ф. 1. Р-1.

13. Левенок В.П. Отчёт о полевых работах Верхне-Донской археологической экспедиции Ленинградского отделения ИА АН СССР и ЛОКМ в 1963 году // Архив ИА РАН. Ф. 1. Р-1. 
14. Левенок В.П. Отчёт о полевых работах Верхне-Донской археологической экспедиции Ленинградского отделения ИА РАН СССР и ЛОКМ в 1964 году // Архив ИА РАН. Ф. 1. Р-1.

15. Левенок В.П. Неолитические поселения на p. Матыре под Липецком // Краткие сообщения Института археологии. Вып. 111. М.: Наука, 1967. C. $116-120$.

16. Левенок В.П. Долговская стоянка и её значение для периодизации неолита на Верхнем Дону // Материалы и исследования по археологии СССР. Т. 131. М.: Наука, 1965. С. 223-231.

17. Левенок В.П. К характеристике культур мезолита, неолита и бронзы в Воронежском Подонье // Известия Воронежского государственного педагогического института. Т. 45. Воронеж: Издательство ВГПИ, 1964. С. 142-150.
18. Левенок В.П. Неолит Верхнего Дона и его место среди неолитических культур лесостепной зоны Европейской части СССР: автореф. дис. ... канд. ист. наук. Л., 1969. 19 с.

19. Левенок В.П. Неолитические племена лесостепной зоны Европейской части СССР // Материалы и исследования по археологии СССР. № 172. М.: Наука, 1973. С. 185-197.

20. Левенок В.П. Памятники днепро-донецкой культуры в лесостепной полосе РСФСР // Краткие сообщения Института археологии. Вып. 126. М.: Наука, 1971. С. 108-114.

Статья написана при поддержке гранта РФФИ 18-49-480004 «Поселение Доброе 9 в системе ранненеолитических древностей лесостепного Подонья).

\section{EARLY NEOLITHIC STONE INDUSTRY OF THE UPPER DON}

(C) 2018

Smolyaninov Roman Viktorovich, candidate of historical sciences, head of Archeology and Ethnology Office Yurkina Elizaveta Sergeevna, senior laboratory assistant of Russian and World History Department Lipetsk State Pedagogical P. Semenov-Tyan-Shansky University (Lipetsk, Russian Federation)

Abstract. Features of the flood plain settlements of the river Don watershed and its tributaries is the fact that almost all of them are multi-layered. Until recently it was not possible to talk about the Early Neolithic stone industry of the Upper Don. All conclusions about Early Neolithic material culture in this territory were done by A.T. Sinyuk, based on the Middle-Don site. He described tool industry as blade technique. The paper mentions the most important sites and gives a review of Early Neolithic stone industry of the Upper Don. Nowadays there are materials of the 4 Early Neolithic cultures on the Upper Don territory: Middle-Don (72 sites), Karamyshevo (26 sites), Upper-Volga (4 sites) and Elshanskaya (4 sites) cultures. The earliest materials in the research area date VI mill. cal BC. The data on the stone industries of the Elshanskaya and Upper-Volga cultures in the Upper Don are absent. There are stone collections, which could be connected only with the Middle-Don and Karamyshevo Early Neolithic cultures. This industry could be described as flake technique.

Keywords: Early Neolithic; flint; quartzite; Middle-Don Neolithic culture; Karamyshevo Neolithic culture; Upper Don; radiocarbon dating; tool; flake; forest-steppe; excavation area; site; arrowhead; scraper; knife; polyfunctional tools; blade; core; typological analysis.

УДК 902903023

Статья поступила в редакцию 14.06.2018

\section{НОВЫЕ ДАННЫЕ О РАННЕМ НЕОЛИТЕ СТЕПНОГО ПОВОЛЖЬЯ}

(C) 2018

Юдин Александр Иванович, доктор исторических наук, заместитель директора по научной работе Научно-исследовательский центр по сохранению культурного наследия (2. Саратов, Российская Федераиия)

Выборнов Александр Алексеевич, доктор исторических наук, профессор, заведующий кафедрой отечественной истории и археологии

Самарский государственный сочиально-педагогический университет (2. Самара, Российская Федераиия)

Аннотация. Вопрос выделения раннего неолита на различных территориях является одним из наиболее сложных для исследования. Ранний неолит степного Поволжья долгое время был неизвестен. Это объясняется малочисленностью памятников эпохи неолита в интересуемом регионе. Ситуация изменилась после исследования Варфоломеевской стоянки. Нижний слой этого опорного памятника орловской культуры относился к среднему неолиту, слои 2Б и 2А - к позднему неолиту. Данная версия основывалась на ограниченной источниковой базе и малочисленных радиоуглеродных датах, часть из которых носили дискуссионный характер. Новые полевые исследования 2014-2017 годов на трех раскопах поселения Орошаемое и значительная серия радиоуглеродных дат по различным органическим материалам, полученным в различных лабораториях (включая AMS), позволили пересмотреть периодизацию как Варфоломеевской стоянки, так и орловской культуры в целом. Это позволяет сделать типологический анализ материалов, а также техникотехнологический анализ керамического инвентаря. Так, наиболее ранняя керамика изготовлена из ила с естественной примесью раковин моллюсков. Нижний слой памятника теперь определен как ранненеолитический, слой 2Б - средний неолит, слой $2 \mathrm{~A}$ - поздний неолит.

Ключевые слова: степное Поволжье; Северный Прикаспий; стоянка; ранний неолит; средний неолит; поздний неолит; орловская культура; керамика; каменный инвентарь; стратиграфия; периодизация; хронология; радиоуглеродное датирование; технико-технологический анализ. 